\title{
The Role of Self-Efficacy in the Thesis-Writing Experiences of Undergraduate Honors Students
}

\begin{abstract}
Writing a thesis is often the culminating experience for undergraduate students enrolled in university honors programs in the United States. Because writing a thesis is one of the most difficult academic tasks that an undergraduate student may undertake, it requires a high level of self-efficacy, or belief in one's capabilities to achieve certain results (Bandura 1997). However, the factors that contribute to students' efficacy expectations when writing a thesis are not fully understood. This qualitative study followed 11 honors students over the course of several months in order to understand their experiences as they completed their theses. Data was gathered through a series of four questionnaires and two interviews. Analysis revealed six themes: previous research experiences, emotions, project timelines, structure, advisors, and support networks. These themes suggest that students' abilities to manage their emotions and employ self-regulatory strategies play a critical role in their self-assessments of efficacy during work on challenging academic tasks, findings which have implications for a variety of academic programs and campus support services. In addition, this study reveals that faculty mentoring of undergraduate students may require greater attention to cultivating emotional awareness and regulation than does the mentoring of graduate students.
\end{abstract}

KEYWORDS

self-efficacy, self-regulation, undergraduate research, thesis, emotion

\section{INTRODUCTION}

Undergraduate research projects enable students to conduct authentic investigations into issues within their disciplines. These projects challenge students to use a full range of research and writing skills, which may include, as appropriate for their discipline, developing a research question, designing a study, collecting data, conducting secondary research, analyzing data, and communicating research findings. Undergraduate research projects have been identified as a highimpact educational practice that not only develop skills in research and communication, but also foster student persistence, engagement, and self-awareness (Kuh 2008). These types of projects can provide some of the richest learning experiences for undergraduate students; they can also be very challenging.

One type of undergraduate research project is the honors thesis paper. At many higher education institutions in the United States, honors programs provide students with a variety of rigorous academic experiences that develop leadership, community engagement, creativity, and inquiry. Honors programs help foster undergraduate research skills, and the honors thesis paper is often the culminating experience for undergraduate students enrolled in these programs. At the end of honors students' careers, their research plans have come to fruition through their resilience and 
newly acquired skills. At our institution, honors students are encouraged to take a research skills course that is taught by a librarian and to meet individually with the librarian assigned to their subject to help them develop a strategy for conducting research for their projects. As librarians, we were prompted by our experiences teaching and consulting with honors students to learn more about their experiences and the ways that we and other educators on our campus can assist them. Since honors students come from a variety of disciplines with different research practices, we felt that learning more about their experiences with substantive research projects would give us the opportunity to better understand how to help foster the skills and dispositions necessary for student success.

In particular, we wondered what contributed to students' efficacy expectations in completing these projects. Honors students often complete their research projects in a relatively short amount of time and while taking a full course load. Because writing an honors thesis is one of the most difficult academic tasks that an undergraduate student may undertake, it requires a high degree of selfefficacy, or belief in one's own capabilities to achieve certain results (Bandura 1997). However, the factors that contribute to students' self-efficacy regarding their thesis projects are not fully understood. Thus, this qualitative study focused on honors students' accounts of their experiences as they completed their thesis projects. We collected data through multiple questionnaires and interviews during students' final months of study. Through an exploration of honors students' perceptions of the skills, habits, and mindsets that contributed to completing their theses, this study may help educators identify ways to help both undergraduate students engaged in intensive research projects and any students who are confronted with challenging academic tasks.

\section{LITERATURE REVIEW}

\section{Undergraduate research}

Wenzel (1997) defined undergraduate research as "an inquiry or investigation conducted by an undergraduate that makes an original intellectual or creative contribution to the discipline" (163). There have been calls in recent decades to boost undergraduate research opportunities at universities in the United States. In the late 1990s, the Boyer Commission on Educating Undergraduates in the Research University (1998) advocated for placing undergraduate research at the center of undergraduate education at research universities. Kuh (2008) later identified several high-impact educational practices that increase student retention and engagement, among them undergraduate research. Undergraduate research as a high-impact practice "involve[s] students with actively contested questions, empirical observation, cutting-edge technologies, and the sense of excitement that comes from working to answer important questions" (Kuh 2008, 10).

Undergraduate research projects emphasize the importance of inquiry-based learning in a student's education. With a basis in the theoretical works of Plato and John Dewey, inquiry-based learning stresses the importance of learning to ask good questions over knowing — and notably, memorizing - the "right" answers (Goldman et al. 2010). The emphasis of inquiry-based learning is on the learner rather than the instructor, with the student determining the focus of an investigation that is meaningful to them (Jennings and Mills 2010), often in close collaboration with a faculty member. Students learn to ask effective questions, consider multiple points of view, engage with critical analysis, reflect on their own learning, and collaborate with others in the co-construction of knowledge (Jennings and Mills 2010). With inquiry-based learning, faculty serve as mentors by asking questions of their own, helping students to work through real-world problems, and exposing them to disciplinary approaches to investigation (Goldman et al. 2010; Jennings and Mills 2010). This kind of faculty mentoring is critical in undergraduate research, as it has been shown that the 
supportive interaction that students have with faculty advisors over the course of their researchfrom regular feedback to modeling problem-solving behaviors- has strong positive effects on students (Kuh 2008).

The value of inquiry in undergraduate research is supported by research that has shown that academic, personal, professional, and social development can result from students' participation in these types of projects (Samura 2018). In fact, undergraduate research is beneficial to students across a range of liberal arts educational outcomes (Kilgo, Ezell Sheets, and Pascarella 2015) and is linked to students' persistence to graduation and graduate school aspirations (Kilgo and Pascarella 2016). Studies have also documented students' self-perceived benefits of undergraduate research. Novice researchers from across disciplines perceived gains in their skills and knowledge over the course of an undergraduate research project (Bhattacharyya, Chan, and Waraczynski 2018). In addition to increased knowledge of the research process and improved communication skills, students identified key personal benefits such as developing persistence, self-awareness, selfconfidence, and time management skills (Wolf 2018).

\section{Self-efficacy}

The concept of self-efficacy and its relation to learning was developed by Albert Bandura as part of his social cognitive theory. Bandura (1997) defined self-efficacy as "beliefs in one's capabilities to organize and execute the courses of action required to produce given attainments" (3). Thus, self-efficacy concerns not skills themselves but one's beliefs about those skills and the extent to which one believes that their actions will achieve certain results. Efficacy expectations differ from outcome expectations, which are judgments that certain actions will produce certain consequences (Bandura 1986). In the case of undergraduates writing a thesis, a student might have an outcome expectation that completion of a thesis will enable them to graduate with honors and will earn them praise from faculty and peers. However, a student's belief in their own ability to write a thesis that will sufficiently satisfy their advisor's expectations is an efficacy expectation. Self-efficacy is not based on an objective assessment of abilities; instead, it is closely tied to positive and negative thought patterns, reactions to environmental cues and stressors, and emotional regulation (Pajares 2009).

In learning environments, self-efficacy is closely related to motivation and accomplishment. Students' self-efficacy determines what types of tasks they will undertake, how difficult those tasks are, and how much effort they will exert on those tasks. Students with higher levels of self-efficacy not only take on more challenging academic tasks, but they also work harder on those tasks and persist when things get difficult (Bandura 1986, 1997; Pajares 2009). They are also more inclined to use self-regulatory and self-monitoring strategies, manage their own stress reactions, and maintain a positive attitude when learning difficult material (Bandura 1986, 1997; Pajares 2009).

Bandura identified four main sources of self-efficacy. First, mastery experiences consist of performance accomplishments; that is, students who have successfully completed similar experiences in the past will have stronger beliefs about their ability to complete future tasks. Repeated successes tend to strengthen self-efficacy, whereas repeated failures tend to weaken it. To be successful in strengthening self-efficacy, mastery experiences must be tied to challenging tasks that involve students' acquisition of the knowledge and skills that will enable them to succeed in future situations (Bandura 1986, 1997). Mastery experiences are the most influential of the four sources because "they provide the most authentic evidence of whether one can muster what it takes to succeed” (Bandura 1997, 80). 
Second, vicarious experiences occur when individuals observe others performing tasks in similar situations. Students may gain confidence about their abilities to accomplish tasks when they see others successfully work through challenges and complete them; likewise, they may lose confidence when they witness failures. Social comparisons also influence the judgments that students make not only about their own abilities but about what constitutes the successful completion of tasks. Thus, students' self-efficacy may be strongly influenced by the modeling behaviors of others, including both professors and peers (Bandura 1986, 1997).

Verbal persuasions provide a third source of self-efficacy. Verbal persuasions tend to be most effective in strengthening self-efficacy when they do not consist of empty praise but instead focus on cultivating positive self-assessments and substantive self-improvement. People tend to be most strongly persuaded when the messages come from those perceived to be skilled at the task in question, such as a research advisor (Bandura 1986, 1997). Verbal messages can influence selfefficacy whether those messages are intentional or unintentional, positive or negative. Furthermore, Pajares (2009) explained that "it is usually easier to weaken self-efficacy beliefs through negative appraisals than to strengthen such beliefs through positive encouragement" (792).

A fourth source of self-efficacy consists of physiological and emotional states, which include reactions to stress, levels of anxiety, and mood. Positive emotions and moods can strengthen selfefficacy while negative emotions and moods can weaken it. Not only do physiological and emotional states affect self-efficacy, but the ways that individuals interpret and respond to these states is also critical and can in turn be affected by self-efficacy levels. Students with stronger self-efficacy may be more successful at managing stress and harnessing their emotions for productive outcomes, while students with weaker self-efficacy may be more prone to feeling anxiety. In addition, students react differently to varying levels of stress; some students may view certain types of physiological arousal as motivating, whereas others may view it as debilitating (Bandura 1986, 1997; Pajares 2009).

\section{Self-efficacy and the undergraduate thesis-writing experience}

Much of the literature on thesis writing has addressed research at the graduate, and particularly doctoral, level. Some studies of doctoral students include a focus on research selfefficacy, "the degree to which an individual believes she or he has the ability to complete various research tasks" (Bieschke, Bishop, and Garcia 1996, 60). For example, Phillips and Russell (1994) observed a positive correlation between research self-efficacy and both research productivity and doctoral students' perceptions of the research training environment. Doctoral supervision that combines direct task-related guidance with support of personal autonomy is most effective in boosting research self-efficacy (Overall, Deane, and Peterson 2011). A mentoring relationship that matches a doctoral student's mentoring preferences can also positively influence research selfefficacy (Johnston 2015), and relationships with dissertation chairs and committee members can be particularly critical (Burkard et al. 2014). In a study that looked at the research training and experiences of education doctoral students, Faghihi (1998) found "that research self-efficacy is a function of a positive and nurturing research environment and a strong supervisory system of dissertation and mentoring, which in turn can enhance students' success" (64).

Regarding undergraduate or master's research, many studies have focused on interventions that help students complete or improve their theses (Aghaee et al. 2014; Engel 2016; Harding and Leligdon 2017; LaBonte et al. 2017; Miedijensky and Lichtinger 2016; Piekart-Primiano, Regan, and Sacharow 2017). For undergraduate research, it is clear that research self-efficacy plays a strong role in students' decisions to engage in research projects (Shaw, Holbrook, and Bourke 2013). However, much of the research in this area does not directly address self-efficacy but touches on issues related 
to it, such as having a good relationship with a thesis advisor, which is related to Bandura's verbal persuasions, and having substantive research experience prior to beginning the thesis, that is, mastery experiences. For example, Wu et al. (2017) explored the behaviors of undergraduate thesis writers, describing the processes students go through and linking the different stages of the thesis to associated thoughts and feelings. Schermer and Gray $(2012)$ conducted a study of the senior capstone research experience at four liberal arts colleges, describing factors that make it a positive or negative experience, such as programmatic features, advisor relationships, prior courses, student stress and workload, and student development.

While it is clear that undergraduate research projects like the honors thesis provide valuable educational opportunities for students, many students do not complete these projects because they are so challenging. Therefore, more information is needed regarding the factors that ensure that they are successful experiences, including students' self-efficacy. Thus, this study was designed to answer the following research questions: How do honors undergraduate students understand their experiences with the process of writing a thesis? And how do their perceptions of their skills, habits, and mindsets relate to the four sources of self-efficacy that Bandura described?

\section{METHOD}

\section{Setting and participants}

We conducted this research at a mid-sized public university in the United States that has a student enrollment of approximately 21,500 students. The research project was approved by our university's Institutional Review Board. This study is also part of a larger project that examined honors students' experiences of self-efficacy in relation to various aspects of the thesis-writing experience, including their experiences with information literacy (Medaille et al. 2021). Our university's honors program enrolls about 450 students from all majors. Honors students take designated honors courses, maintain a high grade point average (3.25 out of 4.0), and participate in experiential learning opportunities. Students also conduct research for a thesis project which has a substantial written component during their final two semesters of study. As part of this experience, students work closely with a faculty advisor, submit a written work that conforms to program expectations, and present their work in an oral defense before a committee or in a poster session at a local academic gathering.

Eleven full-time honors students in their final year of study agreed to participate. All students were completing a thesis in spring 2019 and had finished their thesis proposal course in the previous semester. We recruited students in November 2018 via an email message sent by the director of the honors program. Interested students completed an online questionnaire. If students met the criteria for the study, we contacted them to set up an initial meeting to explain the project and obtain students' consent. Participants represented a variety of majors: biology, chemistry, economics, English literature, journalism, linguistics, management, mathematics, molecular microbiology and immunology, philosophy, and Spanish literature. Eight of the participants were female; three were male. Participants ranged in age from 20-22. A higher proportion of females were represented in this study, as the honors program make-up was $58 \%$ female.

\section{Data sources, collection, and analysis}

We used two data sources: online questionnaires and interviews. Each of the four researchers involved in the study was responsible for working with two to three participants, which included holding the initial meeting with the students, conducting the interviews, and sending email 
reminders to the students to complete the online questionnaires. All four of the researchers are academic librarians.

In order to track students' feelings about their research over the course of their project, we used questionnaires with prompts for students to reflect on their research. These questionnaires served as a sort of guided research journal. Questionnaires were tested by three library student peer research consultants prior to distribution to the study participants to ensure the questions were understood and that they elicited the information we were seeking. Questions were revised in response to the feedback received from the testers.

Participants completed four online questionnaires spaced several weeks apart, beginning in late November to early December of 2018 and finishing in April of 2019. We distributed the questionnaires using Qualtrics software; each questionnaire took students about 30-45 minutes to complete. The questionnaires consisted of a combination of open- and closed-ended questions and asked students to reflect upon their thesis work over the preceding few weeks. The closed-ended questions asked students to rate their level of confidence with their current progress on their thesis, their ability to find secondary sources, and their ability to write portions of their thesis. Students were also asked to rate their organization levels and their levels of interest in their thesis projects. The open-ended questions asked students about their most recent work on their thesis, including which aspects were most challenging and most helpful, as well as their plans for moving forward. All four questionnaires contained the same set of questions, allowing us to track changes to self-efficacy over the course of the project. In both the questionnaire and in the interviews, we used the word "confidence" rather than the term "self-efficacy" because we thought students would better understand its meaning. See appendix A for the questionnaire.

Students also participated in two interviews of about one-hour in length. We used these interviews as a way to explore students' experiences more deeply and to follow up on comments and issues that arose in the questionnaires. We held the first interview in late January or early February when students were in the middle of researching and writing their theses. We held the second interview in April, just as students were finishing their theses. During the interviews we asked students about their topics, their previous research experiences, their relationships with their advisors, their use of outside sources, their methods for staying organized, the support they received from others, the challenging aspects of their projects, the most helpful aspects of their experiences, and what personal qualities helped them complete their projects. We also asked students to discuss their questionnaire responses rating their confidence, organization, and engagement levels and to describe any changes they had experienced. We conducted all interviews in group study rooms in the main campus library and audio recorded them. See appendices $B$ and $C$ for the interview questions.

To conduct the analysis, we exported the questionnaire responses from Qualtrics as Microsoft Word documents, and all interview recordings were transcribed. To analyze the closedended questions from the questionnaire, we created bar graphs for each question and each student. These graphs allowed us to see the changes that each student experienced over the course of the semester. To analyze the interviews and open-ended questionnaire responses, the researchers developed a coding scheme on the basis of a preliminary reading of all of the data as well as major topics that appeared in the self-efficacy literature. After developing an initial coding scheme, we went through two rounds of testing in which the coding scheme was independently applied to one interview and one questionnaire by the researchers. Points of agreement and disagreement were discussed, and the coding scheme was adjusted. Once the coding scheme was finalized, each of the 22 interview transcripts and 44 questionnaire documents was coded by one researcher, with a second researcher assigned to take a second pass of each document to look for and correct any 
coding errors or inconsistencies. We used the comments feature in Word to code all documents, and we copied all coded material into a master coding Excel spreadsheet to allow for data sorting.

As we examined the coded sections, we observed six discrete aspects of students' experiences. One researcher wrote a detailed description of each area using the participants' own language, and each description was reviewed by other team members to check for thoroughness, accuracy, and clarity. In the final analytic phase, we reviewed the descriptions of students' experiences in light of the graphs we had created, and then we analyzed and discussed each description according to the features of self-efficacy theory to generate the six final themes that are described in the next section.

\section{RESULTS}

In analyzing student comments in the interviews and questionnaires, students often used similar language, such as describing some of their experiences as "stressful" or their advisors as "supportive" or "knowledgeable." All quotes used in discussing the results are direct quotes from students, but when similar brief comments came from different students, we have not attributed them specifically. Any unique, unusual, or longer quotes are attributed to particular students.

\section{Students experienced fluctuating emotions that affected their perceptions of their own abilities}

Most students described both positive and negative emotional states related to their thesis, sometimes in the same breath. It was "long and fun," "exhausting and worthwhile," "arduous ... [and] fulfilling." As Student 7 put it, "This was probably the most challenging thing I've done, I think in...my life." The thesis pushed students to their limits, in positive and negative ways.

Negative emotions occurred during periods of uncertainty, when students described the thesis as "scary," "stressful," and "overwhelming." For example, Student 5 said, "I feel like I'm out here in the wilderness." For many students, the thesis project, or important parts of it, were entirely new. They were concerned about their ability to write a "lengthy enough thesis," to advance "my own argument," to "get data," or to "prepare an oral defense." Students needed help navigating the uncertainty and anxiety of the thesis. For example, Student 4 said, "I think something that's not focused on is how mentally stressful the thesis is. And it makes you a little crazy."

High expectations, originating with themselves or their advisors, made some students feel stressed and anxious. For example, Student 5 said, "I feel like it's a thesis, it has to be the best" while Student 11 said, “I just didn't want my thesis advisor to be disappointed in me.” At times, participants doubted their own abilities. Students used words like "psychological hurdle," "freaking out," "so hard," "getting stuck," and "daunting" to describe the pressure they felt when beginning to draft their theses. Sometimes the desire to do well resulted in what Student 5 called "perfection paralysis." Students described feeling so much pressure to "say something meaningful" that they often delayed working on their thesis.

Positive emotions occurred during moments when students sensed a breakthrough in their work. At these times, students reported feeling “excited," "relieved," and "confident." Most students expressed a sense of accomplishment as they neared completion of their thesis. For Student 4, the thesis demonstrated the culmination of her time at the university: "It's meant a lot. And it's also this concrete thing that shows what I've been doing with my life the past couple of years." Completing a thesis and overcoming the emotional "ups and downs" along the way was a meaningful experience for most students. 


\section{Good advisors not only provided research and professional expertise, but also developed relationships that provided emotional support, encouragement, and personal connection}

Positive support from advisors was a key factor in having a good thesis experience. According to Student 4, a good advisor "makes or breaks your thesis." Good advisors established clear and open lines of communication, provided guidance on the project, were supportive of students' emotional needs, and acted as mentors. Such advisors were not only "knowledgeable," but "supportive," "encouraging," and "really, really helpful." For most students, just knowing that their advisor was available to discuss their thesis with them was important.

Students appreciated the research guidance they received, and several commented on how helpful their advisors were in pointing them to particular works, authors, or research studies relevant to their fields. The advisors' willingness to share their knowledge of the literature and research practices of their disciplines helped guide participants as they reviewed prior literature and refined their research methods. For example, Student 4's advisor "helped me pick out a suitable method of analysis that I would not have heard of otherwise." Advisors helped students keep their research topics on target and manageable, such that the size of their projects could be completed in a reasonable amount of time.

Advisors also frequently served as professional mentors for students, helping them grow as scholars. Student 2 commented that their advisor was "focusing on expanding my name as a scholar and I think that's one of the most helpful things that anyone could do for me." Several advisors either were co-writing articles with participants or gave advice about how to get published on their own, helping them choose potential journals and understand the scholarly publishing process. Others encouraged participants to present their research at conferences and aided them in refining their presentations.

Many students valued their relationship with their advisors and developed an appreciation for them as people as well as scholars. As Student 8 said, "you can discover for yourself that they're just as cool as you." Advisors also supported students through the emotional dimensions of thesis research by helping them to manage stress and relieve pressure. For example, Student 1 described how their advisor was emotionally supportive: "I was struggling with writing things. She checked in and said, 'Hey, how are things going? If you need me, I'm here.”' Several students also developed strong personal connections with their advisors. As Student 3 said, "He kind of changed from my thesis advisor to just my [life] advisor."

\section{Previous research experiences immersed students in disciplinary scholarship and communication which facilitated their research and writing}

Some of the students' confidence in their abilities came from previous disciplinary research experiences that helped them to learn ways of thinking, acting, and communicating within a community of disciplinary scholars. For example, previous disciplinary experiences helped Student 9 "realize the importance of my speaking the language that they speak," and helped Student 2 to learn "how I should direct myself in academia and as a scholar." These experiences often came from taking classes within their disciplines that helped them to learn the language, theory, and research methods of that discipline, all of which facilitated later research. Classes in research methods were noted as being particularly helpful because they allowed participants to gain familiarity-depending on their discipline - with issues like study design, survey methods, statistical methods, data gathering, data handling, lab techniques, and analytical software. In addition to learning about research methods, 
students also learned the relevant theory, vocabulary, citation styles, and writing styles and conventions used within their disciplines.

Students also benefited through previous disciplinary immersion that occurred outside of their classes. The most common types of these experiences occurred through working in research labs, but they also came from doing community work, participating in research internships or fieldwork with a professor, participating in conferences, or authoring/co-authoring papers. A few students discussed the value of presenting papers and posters at conferences and conversing with others in the field. These research experiences not only gave students first-hand experience with conducting research, but they also immersed them in a research environment that ensured that research came "naturally" to them when they began working on their thesis.

Students who had not had previous research experiences in or outside of the classroom reported struggling. In previous classes they might not have learned how to use academic journals or synthesize research from multiple sources, and the process of data collection and analysis tended to be less frequently addressed. For example, Student 5 lamented, "I wish that I had done more research projects in my liberal arts degree. No one even suggested it." They clarified that "I did research projects ... in the sense that I looked for information, whereas this I feel is different because I have to collect data and analyze the data and synthesize the data." Several students discussed challenges with understanding source material, recognizing that their lack of background knowledge or familiarity with disciplinary vocabulary contributed to this difficulty. Even when they had substantive previous research experiences, participants still faced several challenges with aspects of disciplinary communication, such as learning the writing styles and conventions associated with their disciplines. This included knowing how and when to quote, how to explain results, how to discuss statistics, how to cite sources, how to use disciplinary terminology, how to convey results visually, and how to avoid passive writing.

\section{A sense of limited time increased students' stress levels and contributed to a sense of helplessness}

Most participants felt that two semesters was not enough time in which to complete their thesis from start to finish. Feeling that they did not have enough time increased their stress, often making it difficult for them to master their emotions. Many participants described how "there hasn't been enough time" to do as well as they would have liked, and they wanted "a lot more time to really craft the thesis." Working on the thesis simultaneously with other end-of-the-year projects and tasks was a frustration for many. Participants expressed a desire for more hours in the week and noted they had "too many things" happening at once. Student 1 stated, "It is simply unfeasible" to work on the thesis with all their other academic tasks. Participants juggled graduate applications, full course loads, and research assistant jobs while completing their theses. Some participants mentioned not being able to work on the thesis during the first semester because "too many things" were happening and they were "doing too much stuff," which left them with too much to do for their thesis in the second semester. Student 4 quit a job because they did not have enough time to focus on their thesis.

Many participants were frustrated with waiting for funding, data collection, or approval from the institutional review board for human subjects research. Some participants wished they had started on their literature reviews earlier in the process, and they wanted more time to read and gather background research before developing other parts of the thesis. Many participants were, in the words of Student 5, "super-preoccupied about the ridiculously short data collection time period." Some worried that they would not have enough time to analyze their data. 
A few participants who were able to finish parts of the thesis early felt that they had enough time to complete the project. Student 7 said, "As far as the process of getting it done and finishing writing, I felt confident on that ... I think I was one step ahead of my friends because I ... [started] back in April." Other participants mentioned time advantages such as using academic breaks to write large portions, not having to get institutional review board approval, and being familiar with lab procedures through previous projects. A few students also spoke about committing to a specific topic early in the process, collecting samples early, or working with data that was readily available.

\section{Structure, whether internally or externally imposed, helped students manage their emotions}

Because of the size of the project, most participants found that they needed some kind of internally or externally imposed structure to help them complete their theses. Structural elements included scheduling time for working on the thesis and meeting smaller, periodic deadlines. Such structure provided accountability and helped students to manage their stress levels, not feel overwhelmed, and gain confidence when meeting mini deadlines. Some structure was provided by the honors program, but students more commonly described forms of structure that were selfimposed.

All participants identified personality traits or preferred ways of working that demonstrated a self-understanding that helped them complete their theses. Some used a due date calendar or developed a spreadsheet with deadlines to create more structure for themselves. Student 7 said, "Making a timeline for myself has helped me the most. It has relieved a lot of stress when thinking about the project because I have factored everything into this timeline, even allowing two to three days for printing the thesis itself." Learning how to break down their projects into "manageable chunks" helped to ensure that they did not feel overwhelmed and made steady progress. Several students created writing routines, such as writing for 30 minutes or two hours at a time or writing a certain number of pages each week. Student 4 hoped to "do something with the thesis every single day." One student described using a phone app to disable distractions while they were writing.

While much structure was internally imposed, participants responded positively to the formal structures externally imposed by the honors program. Chapter deadlines and regular feedback helped provide "that extra bit of accountability." Regularly scheduled meetings helped boost confidence, and chapter deadlines helped participants "keep pace" and made them feel "on track." Many students described how frequent meetings with their advisors provided them with the structure they needed to make steady progress. For example, Student 11 described, "I knew every two weeks I had to have a good chunk of stuff done ... and then that kept the project moving." At the same time, some students still craved more formal structure at the programmatic level. Many participants felt a "lack of true structure," making it hard to keep themselves on track. There was a sense that the process was "more ambiguous than [they] would like it to be," and several longed for the use of more formal visual calendars, roadmaps, templates, and guidelines. Most participants wanted the honors program to give them "stricter deadlines," "detailed timelines," and "hardcore timeline planning sessions" to help get them through the thesis.

\section{Both formal and informal support networks helped students to feel less alone}

A strong and reliable network was important to students throughout the time they spent working on their theses. Most students described feeling "alone" and "on my own" when writing their thesis. In the words of Student 9, it is "just so independent." Developing a "broad support system" was crucial to both the actual thesis work and handling the stress of completing a thesis. As 
Student 2 stated, "Having a network that believes in you on the one hand and also has the resources to allow someone [to] create a really good project is incredibly helpful." Formal supports"librarian, mentors, writing consultations, all of it" - were helpful to most students. In addition to working with a thesis advisor, students were required to consult with peer writing tutors during this time-a requirement which many participants found valuable. They described the writing tutors as "amazing," "super helpful," and "very comforting and supportive." These writing consultations often went beyond the mechanics of writing into personal support and encouragement. As Student 1 said, "It's not just the writing. It's about how I'm doing too."

Informal support was also important. Student 3 mentioned the value of "having just another person to talk to." Several students discussed "support from my peers" or commiserating with "other honors students." Knowing that their peers were "in the same boat" helped these students feel less isolated. Student 9 remarked on how important strong friendships were in offering support through the thesis process, even when that support was indirect: "It wasn't my honors friends, it's other friends who could give me car rides to campus when I was in dire need." For those students who worked in a lab, the lab itself provided a support community. As Student 10 said, "All the people in the lab have been helping. It's all sort of like a team thing, so it's not all on me."

A few students commented that they wished that the honors program built in some way for thesis writers to get together outside of classes. Student 5 commented, "It would be nice if we had some informal meeting time, where we could just chat and decompress." Student 1 felt reassured that others were going through the same challenges, "It feels like these students who are doing this probably have all the very similar kinds of struggles and issues." Having the opportunity to "workshop with each other" and share their common challenges would have been welcomed by some students. As Student 4 said, "I think that would help a lot because a lot of people ... feel kind of alone and scared and lost... But I think just having a little bit more of a sense of everybody's doing this, it'd be really nice." In addition to structured deadlines and required meetings, students wanted time just to talk.

Many students who developed a strong support network expressed how deeply they valued the experience, not only for helping them succeed but for helping them "get out there and build those relationships." The sense of "community" gained stood in contrast to the otherwise solitary thesis endeavor. Like their peers, these students grappled with the loneliness of writing a thesis, but they also found meaning in forming connections around the common purpose of research.

\section{DISCUSSION}

Self-efficacy theory provides a useful framework for understanding why undergraduate students may have successful and rewarding experiences with research projects because it provides a holistic picture of the role of several influential factors that are present within every academic environment. This study revealed six major themes connected to honors students' experiences and perceptions of their own skills, habits, and mindsets.

The table in appendix D demonstrates the possible links between these six themes and the four sources of self-efficacy described by Bandura $(1986,1997)$. Only one of the themes (that concerning previous research experiences) described here relates to mastery experiences, the strongest source of efficacy expectations. Three themes (advisors, research experiences, and support networks) indicate that students were strongly affected by their interactions with advisors and peers, which could suggest that vicarious experiences — that is, observational learning — may play a significant role in the thesis-writing experience. Of note, three of the themes (emotions, timeline, and structure) map directly to physiological and emotional states, and two of the themes (advisors 
and support networks) relate indirectly to emotional states. A strong takeaway from this study is that participants often felt alone and isolated when working on their theses, which contributed to their negative emotional states. While this study does not show a direct link between negative emotions and self-efficacy, the students' fluctuating emotions could potentially have influenced their efficacy expectations.

It should be noted that students' own efficacy assessments do not paint a complete picture of their likelihood to successfully complete a thesis. In fact, it is not uncommon for students to overestimate their abilities due to poor metacognitive and self-monitoring strategies, leading to underperformance on academic tasks (Kruger and Dunning 1999; Talsma, Schüz, and Norris 2019). However, in developing the concept of self-efficacy in learning, Bandura (1977) was interested in the constant interaction that occurs between learners and their environments, writing that his social cognitive theory "neither casts people into the role of powerless objects controlled by environmental forces nor free agents who can become whatever they choose" (vii). Students have some agency over their own learning, which was the primary interest of this study, but the importance of self-awareness (including awareness of one's own deficits) should not be neglected. A good question for educators might be: What can they do to foster personal agency as well as metacognitive skills and selfawareness in students who are working on challenging academic projects? Ideally, these qualities should be complementary.

This study echoes research regarding doctoral students, which found that supportive environments and faculty relationships can help to increase self-efficacy (Burkard et al. 2014; Faghihi 1998). However, these factors may be even more critical for undergraduates, for whom research autonomy (Overall, Deane, and Peterson 2011) may be less important than it is for doctoral students. Not only can a good advisor instruct students in the disciplinary expectations for research and writing, but they can also help to nurture in students the kind of inquiry mindset that is a critical part of these types of advanced projects (Goldman et al. 2010; Jennings and Mills 2010) and that requires cultivation, practice, development of a love of learning, and a nurturing of students' passions and interests.

Self-efficacy theory helps to illuminate why mentoring plays such a critical role in students' research experiences. Faculty who agree to serve as undergraduate thesis advisors should recognize that students may need more than just their scholarly expertise; the personal connection and emotional support that advisors can offer students may be equally important in making research projects rewarding and positive experiences. This study shows that honors students were unprepared for the varying emotions that they experienced throughout the thesis process, and this weakened their confidence. Educators can teach emotional awareness through reflective practices that help students recognize positive and negative emotions so that they can interpret and respond to them. By identifying these feelings, students can link their emotions to the different stages of the research process ( $\mathrm{Wu} 2017)$, thereby gaining a metacognitive perspective on handling research challenges. Such self-regulatory skills can be introduced early in students' academic careers by instructors of research-intensive courses, although they will also need to be reinforced during the research projects themselves.

In addition, undergraduate students may also benefit from additional support networks that are not typically provided for graduate students. Program administrators of capstone experiences or undergraduate research offices can attempt to create supportive peer networks that provide encouragement, nourish positive emotions, and provide peer models of successful research and writing behaviors. These supportive peer networks help to reinforce to students that assistance is 
available to help them overcome obstacles, and that ultimately, they are not alone in these endeavors.

Self-efficacy theory also helps to explain why time pressure and a lack of structure weakened students' confidence in their abilities to complete their research projects. Since undergraduates may be unfamiliar with doing these kinds of advanced research projects, providing more structure can help to ensure that students stay on track and do not lose confidence or momentum when they feel the pressure to perform. Educators may want to address the ways that cultivating self-regulatory processes in undergraduates can help to increase their self-efficacy. Developing time management skills can help students to reduce stress and overcome feelings of helplessness. Students should be encouraged to plan ahead for tight timelines. Program administrators of capstone experiences or undergraduate research offices can encourage students to identify steps that can be done prior to their projects, such as selecting an advisor or taking a research methods class, that can help strengthen a sense of efficacy. Since students often have multiple classes and projects happening simultaneously, learning early how to prioritize tasks is critical. Advisors, writing consultants, and librarians can encourage students to set smaller objectives along the way and break down research tasks into manageable chunks. Instructors of research-intensive courses can model this behavior, scaffold research assignments, and set intermediate deadlines. By teaching time management and self-regulatory skills before a large research project begins, educators can help students develop an organizational method that allows them to take control of the process.

Many educators who have proposed interventions for students working on research projects have, quite logically, focused on providing instruction related to research and writing skills, such as developing topics, identifying appropriate research methods, finding secondary research, and understanding methods for communicating research results (Aghaee et al. 2014; Engel 2016). However, other educators have not only emphasized the importance of teaching research and writing skills, but have also incorporated instruction about self-regulatory processes, including emotion management, goal setting, and time management (Harding and Leligdon 2017; Miedijensky and Lichtinger 2016). With this latter approach educators have also focused on building peer communities that provide students with additional support networks. These peer communities can expose students to vicarious experiences of struggle and success and create opportunities for students to receive verbal encouragement from others (Harding and Leligdon 2017; Miedijensky and Lichtinger 2016). The results of our study of students' self-efficacy suggest that the latter approach - which combines skill development with instruction in self-regulation and the creation of support networks - may be the most beneficial.

It should be noted that this study has some limitations. This exploration of honors students' thesis experiences and perceptions may be most applicable to high-performing students with similar culminating experiences at other institutions. In addition, participants self-selected into this study and may have been more confident in their abilities and therefore more willing to discuss their experiences than their peers. Also, simply being part of the honors program, with its associated academic success and achievement, could have influenced students' perceptions of their abilities, as these previous successful experiences might boost self-efficacy. Nevertheless, this study of students' self-efficacy has several implications for the ways that educators can support both undergraduate students who engage in advanced research projects and all students who are faced with completing challenging academic tasks. 


\title{
CONCLUSION
}

Undergraduate research is a high-impact practice that not only helps students develop advanced research and writing skills but also fosters persistence, engagement, and self-awareness. This study followed 11 undergraduate students during their final months of schooling and identified six major themes related to their self-efficacy in completing one type of undergraduate research project, the honors thesis. Students' previous research experiences, the vicarious experiences gained from seeing others successfully execute research projects, and the verbal encouragement received from advisors, peers, and others were all critical in their ability to succeed. However, students' abilities to manage their own physiological and emotional states were most important. In fact, other aspects of students' experiences - such as their relationships with advisors and peers, the structure and timeline of their projects, and their participation in formal and informal support networksstrongly affected their emotional states. Their own self-regulatory abilities were also critical in influencing their assessments of their own efficacy in completing these challenging projects. Thus, educators should consider the role of emotion and self-regulation when facilitating undergraduate research projects and other challenging academic tasks to ensure that students have successful learning experiences.

\section{ACKNOWLEDGMENTS}

The authors wish to thank Stephen Kemsley, Brie Pegum, and Sarah Brennan at ProQuest for their support of this project.

\author{
Ann Medaille is the Director of Research and Instructional Services at the University of Nevada, Reno Libraries (US). \\ Molly Beisler is the Interim Director of Technical Services in the University of Nevada, Reno Libraries (US). \\ Rayla E. Tokarz is the Information Literacy Librarian at the University of Nevada, Reno Libraries (US). \\ Rosalind Bucy is a Research and Instruction Librarian at the University of Nevada, Reno Libraries (US).
}

\section{REFERENCES}

Aghaee, Naghmeh, Henrik Hansson, Matti Tedre, and Ulrika Drougge. (2014). Learners' Perceptions on the Structure and Usefulness of E-Resources for the Thesis Courses. European Journal of Open, Distance and E-Learning, 17 (1): 154-71. https://doi.org/10.2478/eurodl-2014-0011.

Bandura, Albert. (1977). Social Learning Theory. Prentice Hall.

Bandura, Albert. (1986). Social Foundations of Thought and Action: A Social Cognitive Theory. Englewood Cliffs, NJ: Prentice Hall.

Bandura, Albert. (1997). Self-Efficacy: The Exercise of Control. W. H. Freeman and Co.

Bhattacharyya, Prajukti, Catherine W.M. Chan, and Meg Waraczynski. (2018). How Novice Researchers See Themselves Grow. International Journal for the Scholarship of Teaching \& Learning, 12 (2). https://doi.org/10.20429/ijsotl.2018.120203.

Bieschke, Kathleen J., Rosean M. Bishop, and Victoria L. Garcia. (1996). The Utility of the Research Self-Efficacy Scale. Journal of Career Assessment, 4 (1): 59-75. https://doi.org/10.1177/106907279600400104.

Boyer Commission on Educating Undergraduates in the Research University. (1998). Reinventing Undergraduate Education: A Blueprint for America's Research Universities. https://eric.ed.gov/?id=ED424840.

Burkard, Alan W., Sarah Knox, Terri DeWalt, Shauna Fuller, Clara Hill, and Lewis Z. Schlosser. (2014). Dissertation Experiences of Doctoral Graduates from Professional Psychology Programs. Counselling Psychology Quarterly, 27 (1): 19-54. https://doi.org/10.1080/09515070.2013.821596.

Engel, Steven. (2016). Honors Thesis Preparation: Evidence of the Benefits of Structured Curricula. Journal of the National Collegiate Honors Council, 17 (2): 115-24. 
Faghihi, Foroozandeh. Y. (1998). A Study of Factors Related to Dissertation Progress Among Doctoral Candidates: Focus on Student Research Self-Efficacy as a Result of Their Research Training and Experiences (Publication No. 9834228) [Doctoral dissertation, University of Memphis]. ProQuest Dissertations and Theses Global.

Goldman, Susan. R., Josh Radinsky, Steve Tozer, and Donald Wink. (2010). Learning as Inquiry. In P. Peterson, E. Baker, and B. McGaw (Eds.), International encyclopedia of education ( $3^{\text {rd }}$ ed., 297-302). Elsevier. https://doi.org/10.1016/B978-0-08-044894-7.00495-4.

Harding, Katie, and Lora Leligdon. (2017). Engaging in the Undergraduate Researcher Writers' Process: Creating a Thesis Writers' Bootcamp. In M. K. Hensley and S. Davis-Kahl (Eds.), Undergraduate Research and the Academic Librarian: Case Studies and Best Practices (93-102). Chicago, IL: Association of College and Research Libraries.

Jennings, Louise B., and Heidi Mills. (2010). Inquiry-Based Learning. In Thomas C. Hunt, James C. Carper, Thomas J. Lasley II, and C. Daniel Raisch (Eds.). Encyclopedia of Educational Reform and Dissent (Vol. 1, 466-68). Sage Publications.

Johnston, Ashley E. (2015). Preferred Mentoring Characteristics and Doctoral Students' Research Self-Efficacy (Publication No. 3730350). [Doctoral dissertation, University of Southern Mississippi]. ProQuest Dissertations and Theses Global.

Kilgo, Cindy A., Jessica K. Ezell Sheets, and Ernest T. Pascarella. (2015). The Link Between High-Impact Practices and Student Learning: Some Longitudinal Evidence. Higher Education, 69 (4): 509. https://doi.org/10.1007/s10734-014-9788-z.

Kilgo, Cindy A., and Ernest T. Pascarella. (2016). Does Independent Research with a Faculty Member Enhance Four-Year Graduation and Graduate/Professional Degree Plans? Convergent Results with Different Analytical Methods. Higher Education, 71 (4): 575-92. https://doi.org/10.1007/s10734-015-9925-3.

Kruger, Justin, and David Dunning. (1999). Unskilled and Unaware of It: How Difficulties in Recognizing One's Own Incompetence Lead to Inflated Self-Assessments. Journal of Personality and Social Psychology, 77 (6): 1121-134. https://doi.org/10.1037//0022-3514.77.6.1121.

Kuh, George D. (2008). High-Impact Educational Practices: What They Are, Who Has Access to Them, and Why They Matter. Association of American Colleges and Universities.

LaBonte, Dale, Denise Cross, Fyiane Nsilo-Swai, Matt Bejune, Susan McPherson, and Tiger Swan. (2017). The Honors Colloquium at QCC: A Decade of Experience. In Merinda Kaye Hensley and Stephanie Davis-Kahl (Eds.), Undergraduate Research and the Academic Librarian: (269-79). Association of College and Research Libraries.

Medaille, Ann, Molly K. Beisler, Rayla E. Tokarz, and Rosalind Bucy. (2021). Honors Students and Thesis Research: A Study of Information Literacy Practices and Self-Efficacy at the End of Students' Undergraduate Careers. College and Research Libraries, 82 (1): 92-112.

Miedijensky, Shirley, and Einat Lichtinger. (2016). Seminar for Master's Thesis Projects: Promoting Students' Self-Regulation. International Journal of Higher Education, 5 (4): 13-26.

Overall, Nickola C., Kelsey. L. Deane, and Elizabeth R. Peterson. (2011). Promoting Doctoral Students' Research Self-Efficacy: Combining Academic Guidance with Autonomy Support. Higher Education Research and Development, 30 (6): 791-805. https://doi.org/10.1080/07294360.2010.535508.

Pajares, Frank. (2009). Self-Efficacy Theory. In Eric. M. Anderman and Lynley. H. Anderman (Eds.), Psychology of Classroom Learning: An Encyclopedia (Vol. 2, 791-94). Gale Cengage Learning.

Phillips, Julia C., and Richard K Russell. (1994). Research Self-Efficacy, the Research Training Environment, and Research Productivity Among Graduate Students in Counseling Psychology. The Counseling Psychologist, 22 (4): 628-41. https://doi.org/10.1177/0011000094224008.

Piekart-Primiano, Amanda, Matthew Regan, and Lily Sacharow. (2017). Doing the Honors: Designing a Curriculum for a Year-Long Thesis Project. In Merinda Kaye Hensley and Stephanie Davis-Kahl (Eds.), Undergraduate Research and the Academic Librarian: (69-81). Association of College and Research Libraries.

Samura, Michelle. (2018). Examining Undergraduate Student Outcomes from a Community-Engaged and Inquiry-Oriented Capstone Experience. Scholarship and Practice of Undergraduate Research, 1 (3): 40-47. http://dx.doi.org/10.18833/spur/1/3/15.

Schermer, Timothy, and Simon Gray. (2012). The Senior Capstone: Transformative Experiences in the Liberal Arts (100). The Teagle Foundation. http://www.teaglefoundation.org/Library-Resources/SpecialProjects/The-Senior-Capstone-Transformative-Experiences-in. 
Shaw, Kylie, Allyson Holbrook, and Sid Bourke. (2013). Student Experience of Final-Year Undergraduate Research Projects: An Exploration of 'Research Preparedness'. Studies in Higher Education, 38 (5): 711-27. https://doi.org/10.1080/03075079.2011.592937.

Talsma, Kate, Benjamin Schüz, and Kimberley Norris. (2019). Miscalibration of Self-Efficacy and Academic Performance: Self-Efficacy $\neq$ Self-Fulfilling Prophecy. Learning and Individual Differences, 69: 182-95. https://doi.org/10.1016/j.lindif.2018.11.002.

Wenzel, Thomas J. (1997). What Is Undergraduate Research? Council on Undergraduate Research Quarterly, 17 (4): 163.

Wolf, Lorraine. W. (2018). Undergraduate Research As Engaged Student Learning. New Directions for Teaching and Learning, 2018 (154): 75-85. https://doi.org/10.1002/tl.20293.

Wu, Dan, Wanyu Dang, Daqing He, and Renmin Bi. (2017). Undergraduate Information Behaviors in Thesis Writing: A Study Using the Information Search Process Model. Journal of Librarianship and Information Science, 49 (3): 256-68. https://doi.org/10.1177/0961000616654960. 


\section{APPENDIX A: QUESTIONNAIRE}

Please answer each of the questions below to the best of your ability, thinking about your most recent work on your thesis project. We hope that you will provide detailed responses to these questions so that we can get a thorough understanding of your work on your thesis over the last few weeks.

We expect that this questionnaire will take between 30-45 minutes to complete. If you start it and need to return to complete it later, your answers will be saved.

1. What is your thesis topic?

2. Describe the most recent work that you have done on your thesis (e.g, research, writing, meeting with an advisor, etc.).

3. Please provide enough details to give a thorough picture of the type of work you've been doing. For example, if you did research, did you use print books, online materials, or a particular database? If you collected data, how did you go about doing it (e.g., conducted interviews, did lab work)? If you met with your advisor, what did you discuss? If you wrote part of your thesis, which part did you work on?

4. What external sources have you used for your thesis over the past few weeks? Please be as specific as possible. For example, did you use books, articles, websites, databases? Did you speak with experts? Please give details. For example, if you used web sources, please provide the title of the source and URL.

5. How organized do you feel about your progress on your thesis at this point?

- Very disorganized, I don't know how to get on top of this

- Somewhat disorganized, but not drowning

- Neither disorganized nor organized

- Somewhat organized, but could be better

- Very organized, I'm on top of this

6. How confident do you feel about your progress on your thesis at this point?

- Very unconfident; I'm a bit worried about being able to complete it

- Somewhat unconfident; I have a few doubts but hope I can pull it off

- Neither confident nor unconfident

- Somewhat confident; feeling OK, not bad

- Very confident; I'm sure it will all go well

7. How interested do you feel in your thesis at this point?

- Totally uninterested; I would rather do anything else than work on my thesis project

- Somewhat uninterested; my topic is not the most exciting thing in the world

- Neither interested nor uninterested

- Somewhat interested; I like my topic and project plan 
- Very interested; I love working on this project

8. How confident do you feel that you can find good information sources for your thesis at this point?

- Very unconfident; I have no idea where to look

- Somewhat unconfident; I think I can find some sources but not everything I need

- Neither confident nor unconfident

- Somewhat confident; I can find some good information sources

- Very confident; I have no problem finding the information sources that need

9. How confident do you feel that you can write the required portions of your thesis at this point?

- Very unconfident; I'm not a good writer

- Somewhat unconfident; I have some doubts about writing it

- Neither confident nor unconfident

- Somewhat confident; I feel like I should be able to write it well

- Very confident; I'll have no problem writing a spectacular thesis

10. What has been the biggest challenge that you've encountered in working on your thesis project over the last few weeks? Please be as specific as possible.

11. What has been the easiest part of working on your thesis project over the last few weeks? Please be as specific as possible.

12. What helped you the most in the last few weeks when working on your thesis project? Please be as specific as possible.

13. What would make your work on your thesis project go more smoothly? Please be as specific as possible.

Looking forward...

14. Which parts of your thesis project will you work on in the coming weeks?

15. What are you looking forward to working on in regard to your thesis project in the next few weeks?

16. What are you worried about with your thesis project in the next few weeks? 


\section{APPENDIX B: FIRST INTERVIEW QUESTIONS}

1. In the questionnaire you indicated that your topic is . Please tell me more about it. How did you decide upon this topic? What have you done so far for your thesis and where are you now in the process of working on it? (e.g., using outside research sources, collecting data, writing sections, etc.)

2. Please describe some of the experiences that you have had with conducting a research project in your college career up until this point. Can you give some specific examples?

What has been the most helpful experience? How do you feel that previous research experiences in college have or have not prepared you for working on the Honors thesis project?

3. How do you feel that your thesis is going at this point? In the questionnaire you mentioned that you feel ___ confident about completing your thesis. Are you still feeling this way? And can you explain why? In the questionnaire you mentioned that you feel interested in completing your thesis. Are you still feeling this way? And can you explain why?

4. Can you describe your relationship with your thesis advisor? You don't need to share their name, but just tell me about the relationship you have with them. How did you come to select them as your advisor?

5. What kinds of feedback have you received from your thesis advisor? Can you give a specific example?

6. What kinds of outside sources are you using for your thesis? Have you been able to find good sources? How do you determine which sources to use?

7. Can you think back to the last research that you did where you found a helpful source? Using this laptop, can you walk me through that recent search? And if it's OK, I'd like to record the screen. And could you "think aloud" as you show me how you found your sources? (Record screen capture)

8. How did you learn to find outside sources?

9. What has been the most and least challenging aspects of finding outside research sources?

10. How do you keep track of your sources? Please describe the process you use to read through secondary research and synthesize it in your thesis. Do you take notes from your sources? If so, what process do you use?

11. In the questionnaire, you mentioned that was challenging. Do you still feel this way? Please explain. When you find that a particular task is challenging, how do you go about completing it?

12. What do you plan to do next in completing your thesis?

13. Is there anything else that comes to mind about your thesis that we haven't discussed here? Do you have any questions for me? 


\section{APPENDIX C: SECOND INTERVIEW QUESTIONS}

1. How are you feeling about your thesis project at this point? Please explain.

2. In the questionnaires you mentioned that you feel confident about completing your thesis at this point. (Possibly in addition: Your confidence level seems to have varied/decreased/increased throughout the semester). Can you explain why you've felt this way? You also mentioned that you feel ___ confident about finding good information sources and about writing your thesis. (Note whether this has varied over the semester.) Can you explain?

3. In a recent questionnaire/last interview you mentioned that ___ has been challenging. Do you still feel this way? What did you do to overcome this challenge? Please explain.

4. What have you enjoyed most about conducting your thesis project? And least?

5. Which information research source, other than a person, did you find most helpful in preparing your thesis? It could be a book, article or something else. How did you find it?

6. Has anything changed in your process of finding research sources over the course of this semester? If so, what have you learned?

7. Using this sheet of paper, can you write out an outline of the parts of your thesis? Can you describe the different parts of your thesis and how you approached writing each part? Which part did you find to be most challenging? Why?

8. Last time we talked about your relationship with your thesis advisor. Now that you're close to the end, how would you assess that relationship?

9. How would you assess the support you've received from others, such as the honors program, writing consultants, or from your peers? In other words, have you received guidance or support from people other than your advisor?

10. Last time we talked about your method of staying organized. Has this changed at all?

11. Looking back, what has this thesis project meant to you? Are you happy with your effort on this project? What have you gotten out of this experience, or learned from it?

Are you glad that you did it? Why or why not?

12. What qualities in yourself do you feel were most helpful in enabling you to complete (or almost complete) this project?

13. What has helped you most during your thesis project? This could be a person, tool, website, or something else. Please describe. Looking back, what prior experiences do you feel were most helpful in enabling you to complete (or almost complete) this project?

14. Using this sheet of paper, could you draw something that captures this thesis project for you? It need not be anything elaborate or clever or demonstrate any great artistic skill. But in a minute or 
two, could you draw a picture of whatever comes to mind about your thesis project? Please explain your drawing.

15. Looking back, what word or two comes to mind when you're thinking about your thesis process?

16. Now that you're at the end, is there anything you would have done differently on your thesis?

17. Now that you're at the end, what advice would you give to another honors student who is about to start working on their thesis?

18. Is there anything else that comes to mind about your thesis that we haven't discussed here? 


\section{APPENDIX D. RELATION OF THEMES TO SELF-EFFICACY SOURCES}

\begin{tabular}{|l|l|l|l|l|}
\hline & \multicolumn{3}{|c|}{ Self-efficacy sources } \\
\hline Theme & $\begin{array}{l}\text { Mastery } \\
\text { experiences }\end{array}$ & $\begin{array}{l}\text { Vicarious } \\
\text { experiences }\end{array}$ & $\begin{array}{l}\text { Verbal } \\
\text { persuasion }\end{array}$ & $\begin{array}{l}\text { Physiological and } \\
\text { emotional states }\end{array}$ \\
\hline $\begin{array}{c}\text { Students experienced fluctuating emotions that } \\
\text { affected their perceptions of their own } \\
\text { abilities }\end{array}$ & & & $\mathrm{X}$ \\
\hline $\begin{array}{c}\text { Good advisors not only provided research and } \\
\text { professional expertise, but developed } \\
\text { relationships that provided emotional } \\
\text { support, encouragement, and personal } \\
\text { connection }\end{array}$ & $\mathrm{X}$ & $\mathrm{X}$ & $\mathrm{X}$ & \\
\hline $\begin{array}{c}\text { Previous research experiences immersed } \\
\text { students in disciplinary scholarship and } \\
\text { communication which facilitated their } \\
\text { research and writing }\end{array}$ & & $\mathrm{X}$ & $\mathrm{X}$ \\
\hline $\begin{array}{c}\text { A sense of limited time increased student's stress } \\
\text { levels and contributed to a sense of } \\
\text { helplessness }\end{array}$ & & $\mathrm{X}$ & $\mathrm{X}$ \\
\hline $\begin{array}{c}\text { Structure, whether internally or externally } \\
\text { imposed, helped students manage their } \\
\text { emotions }\end{array}$ & & & & \\
\hline $\begin{array}{c}\text { Both formal and informal support networks } \\
\text { helped students to feel less alone }\end{array}$ & & & \\
\hline
\end{tabular}

\section{ब०}

Copyright for the content of articles published in Teaching \& Learning Inquiry resides with the authors, and copyright for the publication layout resides with the journal. These copyright holders have agreed that this article should be available on open access under a Creative Commons Attribution License 4.0 International (https://creativecommons.org/licenses/by-nc/4.0/). The only constraint on reproduction and distribution, and the only role for copyright in this domain, should be to give authors control over the integrity of their work and the right to be properly acknowledged and cited, and to cite Teaching \& Learning Inquiry as the original place of publication. Readers are free to share these materials-as long as appropriate credit is given, a link to the license is provided, and any changes are indicated. 